\title{
Analysis of the Transient Compressible Vapor Flow in Heat Pipe
}

Jong Hoon Jang and Amir Faghri

Wright State University

Dayton, Ohio

and

Won Soon Chang

Wright Research and Development Center

Wright-Patterson AFB, Ohio

July 1989

Prepared for

Lewis Research Center

Under Contract F336 15-88-C-2820

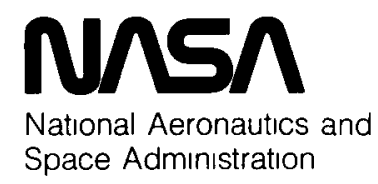




\section{DISCLAIMER}

This report was prepared as an account of work sponsored by an agency of the United States Government. Neither the United States Government nor any agency Thereof, nor any of their employees, makes any warranty, express or implied, or assumes any legal liability or responsibility for the accuracy, completeness, or usefulness of any information, apparatus, product, or process disclosed, or represents that its use would not infringe privately owned rights. Reference herein to any specific commercial product, process, or service by trade name, trademark, manufacturer, or otherwise does not necessarily constitute or imply its endorsement, recommendation, or favoring by the United States Government or any agency thereof. The views and opinions of authors expressed herein do not necessarily state or reflect those of the United States Government or any agency thereof. 


\section{DISCLAIMER}

Portions of this document may be illegible in electronic image products. Images are produced from the best available original document. 


\title{
ANALYSIS OF THE TRANSIENT COMPRESSIBLE VAPOR FLOW IN HEAT PIPES
}

\author{
Jong Hoon Jang* and Amır Faghrı \\ Department of Mechanical Systems Engıneering \\ Wright State University \\ Dayton, $\mathrm{OH} 45435$ \\ and \\ Won Soon Chang \\ Wright Research and Development Center \\ Wright-Patterson AFB, OH 45433
}

\section{ABSTRACT}

The transient compressible one-dimensional vapor flow dynamics in a heat pipe is modeled. The numerical results are obtained by using the implicit non-iterative Beam-Warming finite difference method. The model is tested for simulated heat pipe vapor flow and actual vapor flow in cylindrical heat pipes. A good comparison of the present transient results for the simulated heat pipe vapor Dow with the previous results of a two-dimensional numerical model is achieved and the steady state results are in agreement with the existing experimental data. The transient behavior of the vapor flow under subsonic, sonie, and supersonic speeds and high mass flow rates are successfully predicted. The one-dimensional model also describes the vapor flow dynamics in cylindrical heat pipes at high temperatures.

\section{NOMENCLATURE}

$\mathrm{C}_{\mathrm{p}} \quad$ specific heat at constant pressure, $\mathrm{J} / \mathrm{kg}-\mathrm{K}$

$\mathrm{C}_{\mathrm{v}}$ specific heat at constant volume, $\mathrm{J} / \mathrm{kg}-\mathrm{K}$

$D_{v} \quad$ diameter of the vapor space, $m$

$E_{t}$ total energy of the vapor per unit volume, $\rho\left(C_{v} T+\right.$ $\left.1 / 2 U^{2}\right)$

f friction coetucient at the wall, $\tau_{0} / \rho \mathrm{U}^{2}$

$f_{e}$ friction coefficient at the exit of the evaporator

$f_{t}$ friction coefficient for the fully developed turbulent

flow

h enthalpy, $\mathrm{J} / \mathrm{kg}$

$\mathrm{II}_{\mathrm{fg}}$ latent heat of vaporization, $\mathrm{J} / \mathrm{kg}$

$K$ thermal conductivity of the vapor, $W / m-K$

$L \quad$ length of the heat pipe, $m$

$L_{a}$ length of the adiabatic section, $m$

I ${ }^{\circ}$ length of the condenser, $m$

$\mathrm{L}_{e} \quad$ length of the evaporator, $\mathrm{m}$

M Mach number, $U / \sqrt{\gamma R T}$

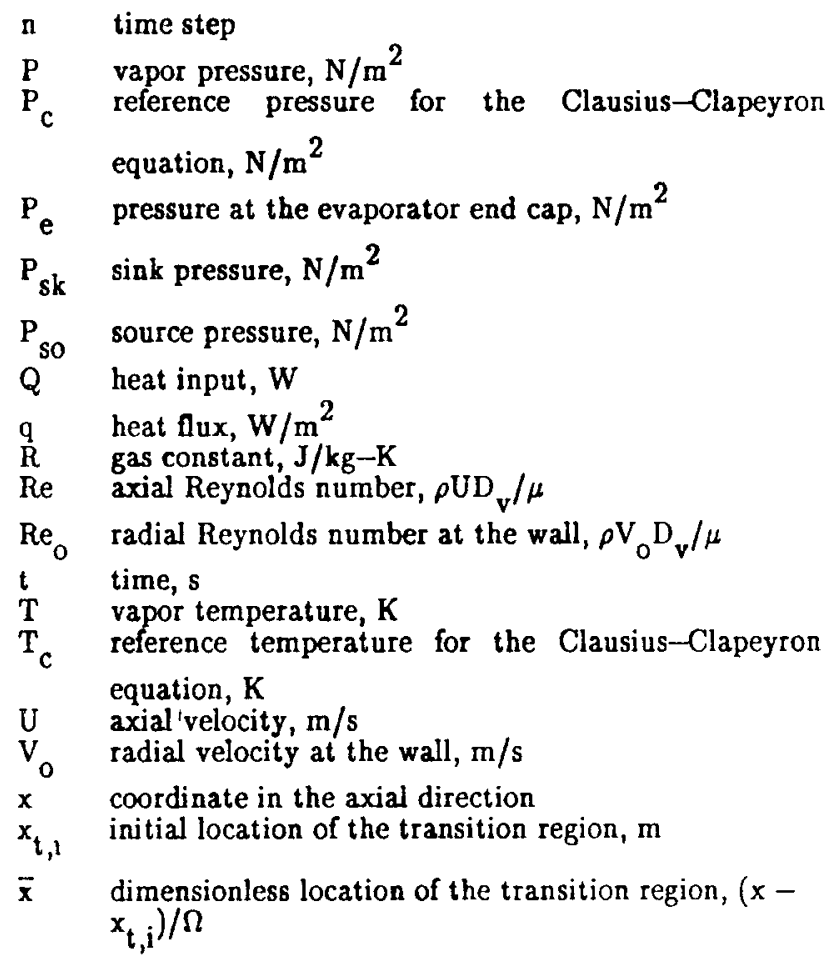

Greck Symbols

$\gamma \quad$ ratio of specific heats, $\mathrm{C}_{\mathrm{p}} / \mathrm{C}_{\mathbf{v}}$

$\delta$ time increment, $\mathrm{s}$

\&x distance between nodes, $m$

$\Gamma$ fraction of transition to turbulent flow

$\mu$ dynamic viscosity of the vapor, $\mathrm{N}-s / \mathrm{m}^{2}$

$\rho$ density of the vapor, $\mathrm{kg} / \mathrm{m}^{3}$

$\tau$ shear stress

$\Omega \quad \mathrm{x}_{\Gamma}=3 / 4^{-\mathrm{x}_{\Gamma}}=1 / 4$

*Presently with Sverdrup Technology, Inc., NASA Lewis Research Center Group, Cleveland, Ohio 44135. 


\section{Subreripts}

propert

perties of the injected or extracted auid at the

$x \quad$ derivative with respect to $x$

\section{INTRODUCTION}

In a heat pipe, the change of phase of the working flud in the closed system is used instead of a large temperature gradient to transport a large amount of energy. The attention of many scientists has focused on this unique phesomenon since the concept was introduced. The vapor from the evaporator carries energy to the condenser, so the vapor flow in the core region of the heat pipe plays an important role in transferring energy from source to sink. Many researchers have studied the steady onedimensional compressible (Levy, 1968; Brovalsky et al., 1976; Faghri, 1988; and Jang, 1988) and the steady two-dimensional vapor flow in heat pipes (Bankston and Smith, 1972; Tien and Rohani, 1974; Ooijen and Hoogendoorn, 1979; Faghn, 1986; and Faghri and Parvani, 1988). The cominon cross sections of the vapor space are curcular, rectangular (Jang, 1988, Oo1jen and Hoogendoorn, 1979), and annular (Faghri, 1986, Faghri, 1988; and Faghri and Parvani, 1988) and are chosen based on the particular application The heat flux distributions on the surface of the evaporator and condenser are uniform except for those presented by Jan J $_{6}$ (1988) Recently, the transient two-dimensional compressible simulated vapor flow in heat pipes (Bowman, 1987, and Bowman and Hitchcock, 1988) was solved numerically, and the expenmental data for the steady state sımulated heat pipe vapor flow was obtained by Bowman (1987) However, the vapor flow was not actual vapor flow in a heat pipe and the numerical and experımental data were presented only in terms of the pressure. The transient two-dimensional compressible vapor flow in a heat pipe with a rectangular cross section diso was studied numencally by Issacci et al. (1988), but only the axial and radial velocity profiles were presented No comparison with the existing experumental data was made and the transient behavior of vapor flow in a heat pipe was not described

During the start-up of high temperature heat pipes, the extremely small density of the vapor causes the vapor flow to at tain sonc and supersonic velocities for a relatively small heat input Thus, the correct description of the transient vapor flow is essential to predict the successful start-up and to estimate the overall performance of the entire heat pipe The governing equations for the vapor flow as well as those for the wall and wick regions should be solved simultaneously. Also, the development of the one-dimensional transient model for the vapor flow has been suggested due to the large amount of computer time required for the two-dimensional model (Bowman, 1987, and Bowman and Hitchcock, 1988) For this purpose, a simple and efficient mathematical model is desired for each region All previous one-dimensional models for vapor flow are for the steady state condition and the viscous dissipation was neglected, which is important for high temperature applications

This paper describes the mathematical model and the numerical method of solution for the transient compressible one-dimensional vapor flow in the heat pipe A comparison of the numerical results with the simulated transient two-dimensional numerical results and experimental data for the steady state given by Bowman (1987) is also presented In addition, the numencal results from the present model for the actual vapor flow in the cylindrical high temperature heat pipe are compared with the experimental data obtaned at the steady state by Ivanovskil et al (1982)

\section{MATHEMATICAL MODELING}

The on -dimensional transient compressible vapor low is considered to predict the vapor flow dynamics in the heat pipe Even though a uniform velocity is used, the friction at the interface is incorporated by using the expressions for the friction coefficients which are found from the two-dimensional numerical results given by Bowman (1987). The viscous dissipation in the vapor region is included and the vapor is assumed to be a perfect gas. The governing equations for the vapor flow in the heat pipe with negligible body forces are formulated by using the principles of the conservation of mass, momentum, and energy in a control volume of cross-sectional area, $\pi D_{V}^{2} / 4$, and width, dx.

The governing equations are written in a compact vectorial form as follows:

$$
\frac{\partial \mathrm{D}}{\partial \mathrm{t}}+\frac{\partial \mathrm{E}(\mathrm{D})}{\partial \mathrm{x}}=\frac{\partial}{\partial \mathrm{x}} \mathrm{F}\left(\mathrm{D}, \mathrm{D}_{\mathrm{x}}\right)+\mathrm{G}
$$

where

$$
\begin{aligned}
& \mathrm{D}=\left[\begin{array}{c}
\rho \\
\rho \mathrm{U} \\
\mathrm{E}_{\mathrm{t}}
\end{array}\right] \\
& E(D)=\left[\begin{array}{c}
\rho U \\
\rho U^{2}+P \\
U\left(E_{t}+P\right)
\end{array}\right] \\
& F\left(D, D_{x}\right)=\left[\begin{array}{c}
0 \\
\frac{4}{3} \mu \frac{\partial U}{\partial x} \\
\frac{4}{3} \mu \frac{\partial U}{\partial x} U+K \frac{\partial T}{\partial x}
\end{array}\right] \\
& G=\left\{\begin{array}{l}
\frac{4}{D_{v}} \rho_{o} V_{o}(x) \\
-\frac{2 \rho U^{2} f}{D_{v}} \\
\left\{\frac{4 \rho_{0} V_{o}(x)}{D_{v}}\left[h_{0}(x)+\frac{v_{o}^{2}(x)}{2}\right]\right\}+
\end{array}\right.
\end{aligned}
$$

$\left.\frac{2 \rho \mathrm{U}^{2} \mathrm{f}_{\mathrm{U}}}{\mathrm{D}_{\mathrm{v}}}\right]$

where $V_{0}(x)$ refers to the velocity at the wall with a positive value for injection and a negative value for suction The equation of state is employed to relate the density, pressure, and temperature in the vapor space as follows

$$
\mathrm{P}=\rho \mathrm{RT}
$$

For the simulated heat pipe vapor flow, the temperature was evaluated by using the equation of state because a change of phase was not involved For the actual vapor flow in the cylindrical heat pipe, the Clausius-Clapeyron 
relationship was used to predict the saturation temperature of the vapor from the pressure as given by

$$
\mathrm{T}=\frac{1}{\mathrm{~T}_{\mathrm{c}}-\frac{\mathrm{R}}{\mathrm{H}_{\mathrm{fg}_{\mathrm{g}}} \ln } \frac{\mathrm{P}}{\mathrm{P}_{\mathrm{c}}}}
$$

The known boundary conditions at the ends of the heat pipe are as follows:

$$
\begin{array}{llll}
U=0 & \text { at } & x=0 \text { and } & L \\
\frac{\partial T}{\partial x}=0 & \text { at } & x=0 \text { and } L
\end{array}
$$

The conditions for the density and pressure at the ends of the heat pipe are unknown, so physically realistic boundary conditions should be derived. In general, near the ends of the heat pipe the mass flow rate is $8 \mathrm{mall}$, so the axial gradients of the pressure and density are small. In the region adjacent to the exit of the evaporator, the variations of the pressure and density are large. Thus, the boundary conditions for the pressure and density can be assumed as follows:

$$
\begin{array}{llll}
\frac{\partial \mathrm{P}}{\partial \mathrm{x}}=0 & \text { at } & \mathrm{x}=0 \text { and } & \mathrm{L} \\
\frac{\partial \rho}{\partial x}=0 & \text { at } & \mathrm{x}=0 \text { and } & \mathrm{L}
\end{array}
$$

Bowman (1987) introduced a correlation between the mass Qux at the wall and the pressure drop across a porous tube wall based on experimental measurements for the simulated heat pipe vapor flow. The mass fux $\left(\rho_{\mathrm{o}} \mathrm{V}_{\mathrm{o}}\right)$ at the wall for the simulated heat pipe vapor flow was evaluated by using this correlation:

$\Delta\left(\mathrm{P}^{2}\right)=3.639 \times 10^{9}\left(\rho_{0} \mathrm{~V}_{0}\right)^{2}+1.7015 \times 10^{8}\left(\rho_{\mathrm{o}} \mathrm{V}_{\mathrm{o}}\right)$

where $\Delta\left(P^{2}\right)$ is the absolute value of the difference between the square of the uniform source pressure and the square of the vapor pressure in the blowing section. In the suction section, $\Delta\left(\mathrm{P}^{2}\right)$ is the absolute value of the difference between the square of the vapor pressure and the square of the uniform sink pressure. A change of phase of the working substance was not involved. The uniform source temperature of $300 \mathrm{~K}$ was used for his experiment, but the sink temperature was not specified. To evaluate the terms in braces \{\} in equation (5), the source temperature is used at the blowing section and the vapor temperature is employed at the suction section.

Since the working fluid changes phase at the vapor-liquid interface in actual heat pipes, the temperature at the interface is the saturation temperature, but the temperature in the vapor space may be quite different from the saturation temperature for high temperature heat pipes. For the one-dimensional model, the properties are the area-averaged properties so that the temperature in the vapor space is not the interface temperature but is also not the saturation temperature. The vapor temperature can be evaluated from the energy equation and the saturation temperature corresponding the vapor pressure can be obtained from the Clausius-Clapeyron relationship. However, this saturation temperature is not the actual interface temperature either. The correct estimation of the terms in braces \{\} in equation (5) is uncertain due to using the area- averaged properties. Since a heat pipe is a closed system, the application of the correct values of heat input and output is important. To eliminate this difficulty, terms in braces \{\} in equation (5) are replaced by using the heat flux applied on the surfaces of the evaporator and condenser as follows:

$$
q=\rho_{0} V_{0}(x)\left[h_{0}(x)+\frac{v_{0}^{2}(x)}{2}\right]
$$

\section{FRICTION COEFFICIENTS}

Bowman (1987) measured the turbulence intensity in the simulated heat pipe to determine the characteristics of the vapor flow. For axial Reynolds numbers up to $R e=$ $10^{6}$, laminar flow was observed in the blowing section and was retained in the suction section for axial Reynolds numbers less than $R e=12000$. The transition from laminar to fully turbulent was predicted in the entrance region of the suction section for axial Reynolds numbers greater than $\mathrm{Re}=12000$. Unlike tow in impermeable tubes, laminar How was maintained for axial Reynolds numbers greater than 2000. For the supersonic case in the suction and blowing section the flow remained laminar until a shock wave occurred and then turbulent flow abruptly appeared, which showed that no transition region existed.

Since the mathematical model is one-dimensional, proper expressions for the friction coefficient are necessary to take into account the frictional losses. Bowman (1987) carried out eleven numerical simulations by using the two-dimensional numerical model to evaluate the friction coefficients according to the characteristics of the vapor flow. The following expressions for the friction coefficients including the compressibility effect were correlated by using the friction coefficients obtained from the two-dimensional model. The friction coefficient for laminar now in the condenser or evaporator is

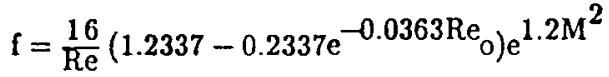

The absolute value of the radial Reynolds number at the wall, $\mathrm{Re}_{0}$, is used in the evaporator and condenser For the adiabatic section where the wall radial Reynolds number is zero, equation (14) is identical to that for the impermeable circular tube. For fully-developed turbulent flow in the condenser, the friction coefficient is

$f_{t}=\frac{0.046}{\operatorname{Re}^{0.2}}\left[1+55 \operatorname{Re}^{0.1}\left(\frac{\mathrm{V}_{\mathrm{o}}(\mathrm{x})}{\mathrm{U}^{0}}\right]^{0.9}\left(\frac{2 \mathrm{~L} \mathrm{c}}{\mathrm{D}_{\mathrm{v}}}\right)^{01} \mathrm{e}^{12 \mathrm{M}^{2}}\right]$

For transition flow in the condenser entrance region, the friction coefficient is defined as

$$
f=f_{t}+\left(f_{e}-f_{t}\right) e^{-0.412 \bar{x}^{-2}}
$$

For the one-dimensional numerical model presented in this paper, the vapor flow in the evaporator and adiabatic sections is assumed to be laminar. In the condenser, laminar Dow is assumed for the axial Reynolds numbers below $\mathrm{Re}=12000$ at the entrance of the condenser and for supersonic flow. When the axial Reynolds number is greater than $R e=12000$, transition and turbulent flows are considered in the condenser. Also, after a shock wave turbulent flow is assumed in the condenser Equation (14) is used to evaluate the friction coefficients in the evaporator and adiabatic sections and is also employed in the condenser when the axial Reynolds number at the entrance of the 
condenser is less than $R e=12000$ and the vapor fow is supersonic. When the axial Reynolds number is larger than $\operatorname{Re}=12000$, equation (16) is applied to the transition region, which is assumed to exist from the entrance of the condenser to about 60 percent of the condenser length based on the experimental data shown in Fig. 3.8 given by Bowman (1987). Equation (15) is used for the turbulent now in the condenser. The initial location of the transition region, $x_{t, i}$, is equal to the location at the entrance of the condenser, and from Fig. 3.8 given by Bowman (1987), $x_{\Gamma}=$ $3 / 4$ and $x_{\Gamma}=1 / 4$ were estimated to be 0.7 and 0.6 , respectively.

\section{NUMERICAL FORMULATION}

From the many schemes (Anderson et al., 1984) available for the solution of the compressible flow problem, the Beam-Warming finite difference scheme is chosen to transform the governing equation (1) to the finite difference formulation. This scheme is a non-iterative implicit method and is similar to ADI for multidimensional low problems by using the factorization which retains the tridiagonal block matrix.

The spatial derivatives are approximated by using the three-point second-order accurate central difference approximation for the interior points and the one-sided second-order accurate difference approximation for the boundary nodes. After the approximation operators are applied, the system of equations becomes

$$
\begin{gathered}
{\left[\mathrm{J}_{\mathrm{i}-1}\right] \delta^{\mathrm{n}} \mathrm{D}_{\mathrm{i}-1}+\left[\mathrm{K}_{\mathrm{i}}\right] \delta^{\mathrm{n}} \mathrm{D}_{\mathrm{i}}+\left[\mathrm{L}_{\mathrm{i}+1}\right] \delta^{\mathrm{n}} \mathrm{D}_{\mathrm{i}+1}=[\mathrm{RHS}]_{\mathrm{i}}^{\mathrm{n}}} \\
\mathrm{i}=2, \ldots, \mathrm{I}_{\max -1}
\end{gathered}
$$

where

$$
\begin{aligned}
& \delta^{\mathrm{n}} \mathrm{D}=\mathrm{D}^{\mathrm{n}+1}-\mathrm{D}^{\mathrm{n}} \\
& {\left[\mathrm{J}_{\mathrm{i}-1}\right]=-\frac{\theta_{1} \delta \mathrm{t}}{1+\theta_{2}}\left[\frac{1}{2 \delta \mathrm{x}}\left([\mathrm{A}]^{\mathrm{n}}-[\mathrm{P}]^{\mathrm{n}}+\left[\mathrm{R}_{\mathrm{x}}\right]^{\mathrm{n}}\right)+\right.} \\
& \left.\frac{1}{\delta x^{2}}[R]^{n}\right]_{i-1} \\
& {\left[K_{i}\right]=[I]-\frac{\theta_{1} \delta t}{1+\theta_{2}}\left[[S]^{n}-\frac{2}{\delta x^{2}}[R]^{n}\right]_{i}} \\
& {\left[\mathrm{~L}_{\mathrm{i}+1}\right]=\frac{\theta_{1} \delta \mathrm{t}}{1+\theta_{2}}\left[\frac{1}{2 \delta \mathrm{x}}\left([\mathrm{A}]^{\mathrm{n}}-[\mathrm{P}]^{\mathrm{n}}+\left[\mathrm{R}_{\mathrm{x}}\right]^{\mathrm{n}}\right)-\right.} \\
& \left.\frac{1}{\delta x^{2}}[R]^{n}\right]_{i+1} \\
& {[\text { RHS }]_{i}{ }^{n}=\frac{\delta t}{1+\partial_{2}}\left[\frac { 1 } { 2 \delta x } \left(-E^{n}{ }_{i+1}+E_{i-1}^{n}+F_{i+1}^{n}-\right.\right.} \\
& \left.\left.\mathrm{F}_{\mathrm{i}-1}^{\mathrm{n}}\right)+\mathrm{G}_{\mathrm{i}}^{\mathrm{n}}\right]+\frac{\theta_{2}}{1+\sigma_{2}} \delta^{\mathrm{n}-1} \mathrm{D}_{\mathrm{i}-\epsilon}\left(\mathrm{D}_{\mathrm{i}+2}^{\mathrm{n}}-\right. \\
& \left.4 D^{n}{ }_{i+1}+6 D^{n}{ }_{i}-4 D^{n}{ }_{i-1}+D^{n}{ }_{1-2}\right)
\end{aligned}
$$

where [I] is the unit matrix, $[A],[P],[R]$ and $[S]$ are the Jacobian matrices, and $\epsilon$ is the coefficient of the dissipative term to damp the oscillation.

This time difference formula reproduces many different schemes with the appropriate choice of $\theta_{1}$ and $\theta_{2}$. The scheme is second-order accurate in time when $\theta_{1}=1 / 2$ $+\theta_{2}$ and first-order accurate otherwise. For $\theta_{1}=1$ and $\theta_{2}$ $=1 / 2$, the formula becomes second-order accurate in time over three grid points. The system of equations, (17), has the following block tridiagonal structure:

$$
[J K L]\left\{\delta^{n} D_{i}\right\}=\left\{\operatorname{RHS}_{i}{ }^{n}\right\}
$$

where [JKL] represents the banded coefficient matrix of which components are $3 \times 3$ matrices for one-dimensional vapor Iow, and $\left\{\delta^{\mathrm{a}} \mathrm{D}_{\mathrm{i}}\right\}$ and $\left\{\mathrm{RHS}_{\mathrm{i}}{ }^{\mathrm{n}}\right\}$ are column vectors. The tridiagonal block matrix size is now $\left(3 \times I_{\max -2}\right) \times(3$ $\left.x I_{\max -2}\right)$ where $I_{\max }$ is the number of nodal points. This system of equations can be solved using the conventional methods for solving block tridiagonal systems of equations. The vector of unknowns at $n+1$ time step is then determined by simply adding $\delta^{n} D$ to the value of $D^{n}$ at $n$ step. The primitive variables $(\rho, \mathrm{U}, \mathrm{P}, \mathrm{T})$ can be obtained from $D^{n+1}$.

A total of 80 nodes, which is the minimum number of nodes to obtain accurate results, are evenly spaced in the axial direction and a time step of $0.1 \times 10^{-3} \mathrm{~s}$ is used for the simulated heat pipe vapor flow. Since the heat flux at the wall in the evaporator is different from that in the condenser due to the different lengths for the cylindrical heat pipe, the coarse nodal system presented some difficulty to reach the steady state. For the cylindrical heat pipe, 200 evenly-spaced nodes are used in the axial direction and a time step of $0.1 \times 10^{-3} \mathrm{~s}$ is employed.

\section{RESULTS AND DISCUSSION}

\section{1) Comparison with the Simulated Heat Pipe Vapor Flow}

A comparison of the numerical results with the experimental data given by Bowman (1987) is desired to verify the mathematical model and algorithm. However, the existing experimental data was obtained by simulating the vapor llow of a cylindrical heat pipe with a porous pipe which has an inside diameter of $1.65 \mathrm{~cm}$ and a length of 0.61 $m$ as shown in Fig. 1. The blowing and suction sections

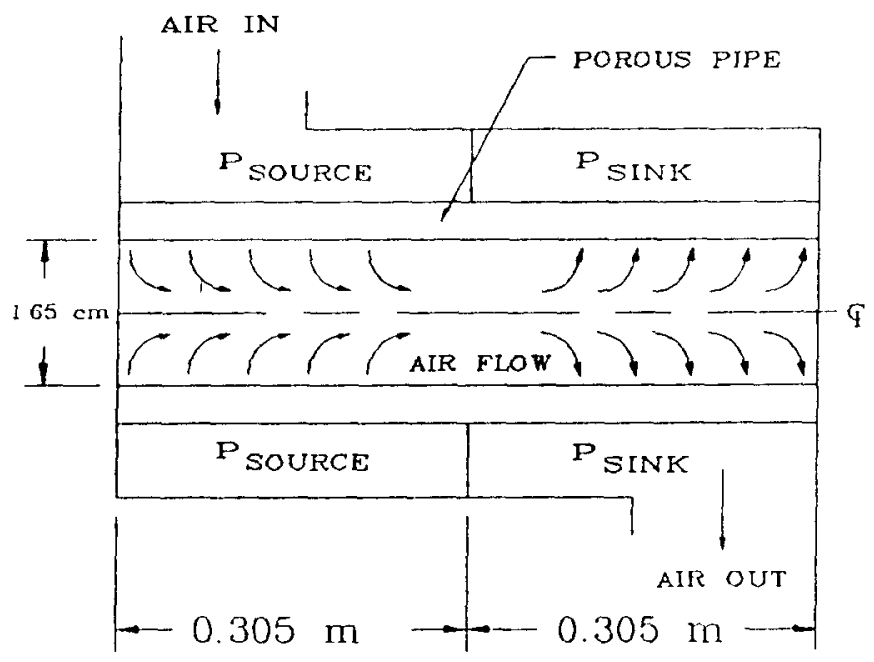

Fig. 1 Schematic diagram of model for air flow in the porous pipe.

have equal lengths and were simulated by the injection and 
suction of air without phase change at the interface. Also, uniform source and sink pressures for the blowing and suction regions are specified instead of the radial mass flow rate. Thus, to simulate the experiment equation (12) is used to obtain the radial mass tux with the known source and sink pressures.

1.1) Transient results. The existing experimental data was obtained at the steady state so the present transient numerical results can only be compared with the transient numerical results for the two-dimensional model (Bowman, 1987). For this purpose, the same geometry and physical conditions are used such as the source pressure of $2.06 \times 10^{5}$ $\mathrm{N} / \mathrm{m}^{2}$ (30 psia) and the sink pressure of $1.03 \times 10^{5} \mathrm{~N} / \mathrm{m}^{2}$ (15 psia) corresponding to case B.1.

Initially, the velocity of the vapor is zero and the pressure and temperature are the same as the source pressure and temperature, respectively. To simulate the transient flow, the sink pressure is suddenly lowered to 1.03 $\times 10^{5} \mathrm{~N} / \mathrm{m}^{2}$ (15 psia), while the source pressure remains the same as the initial pressure. This difference between the source and sink pressures initiates the air llow from the blowing section to the suction section. The pressures at the inlet of the blowing section, the center of the pipe, and the end of the suction section are plotted to compare with the numerical results for the two-dimensional model as shown in Fig. 2.

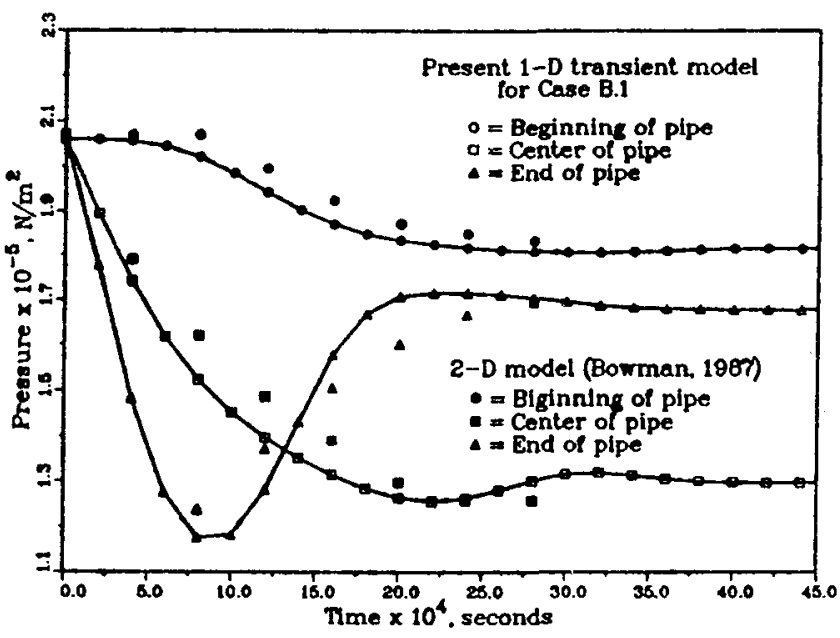

Fig. 2

Comparison of the present numerical results with Bowman's 2-D model for pressure variations with time at three locations of the porous pipe: Case B.1.

Figure 2 shows the following transient behavior of the air flow in the porous pipe. Since the sink pressure is abruptly changed from the initial pressure to $1.03 \times 10^{5}$ $\mathrm{N} / \mathrm{m}^{2}$ (15 psia) along the entire suction section, the pressures at the center and last nodes decrease immediately due to the evacuation of air. For this period, the blowing section pressures adjacent to the suction section start to decrease due to the flow of mass from the blowing section to the suction section, but the pressure near the beginning of the blowing section remains constant. Also, the mass flow rate from the blowing section to the suction section is not sufficient to influence the end of the suction section so that the pressure at this point decreases faster than that at the center of pipe.
At about $0.8-1.0 \times 10^{-3} \mathrm{~s}$, the pressure at the end of the suction section reaches the minimum value and then starts to increase while the pressure at the center of pipe keeps decreasing due to the frictional loss and the acceleration of the flow. At this time, the pressures over the entire blowing section become less than the initial pressure so that the mass flow rate is sufficient to influence the end of suction section. As the pressure in the blowing section decreases and the source pressure remains constant, the mass flow rate from the blowing section to the suction section increases. Thus, the pressure at the center node keeps decreasing and the pressure at the end of the suction section rises due to the contribution of the mass from the blowing section.

At about $3.5 \times 10^{-3} 8$, the pressures at all three points reach the steady state. As expected, the pressure at the end of the suction section does not recover completely due to the frictional loss at the pipe wall. Figure 2 shows that the present results and numerical results for the two-dimensional model (Bowman, 1987) are in agreement.

1.2) Steady state results. When the present numerical results reach the steady state, those results are compared with the experimental data given by Bowman (1987) Numerical calculations are conducted for four different sets (i.e., Cases B.2, B.3, B.4, and B.5) of the source and sink pressures by using equations $(14-16)$ for the friction coefficient. The cases examined are as follows:

Case B.2: $P_{\text {so }}=1.39 \times 10^{5}$ and $P_{\text {sk }}=1.21 \times 10^{5} \mathrm{~N} / \mathrm{m}^{2}$

Case B.3: $P_{\text {SO }}=2.09 \times 10^{5}$ and $P_{s k}=1.57 \times 10^{5} \mathrm{~N} / \mathrm{m}^{2}$

Case B.4: $P_{\text {so }}=2.68 \times 10^{5}$ and $P_{s k}=1.69 \times 10^{5} \mathrm{~N} / \mathrm{m}^{2}$

Case B.5: $P_{\text {so }}=5.30 \times 10^{5}$ and $P_{s k}=1.06 \times 10^{5} \mathrm{~N} / \mathrm{m}^{2}$

Figure 3 shows the comparison of the pressure distributions along the axial direction. The top three lines in Fig. 3 show

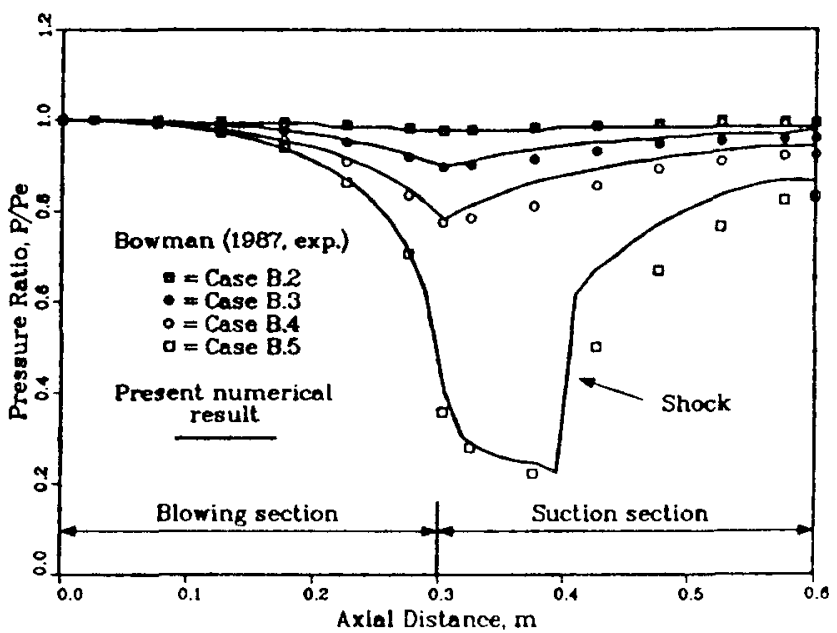

Fig. 3

Comparison of the present numerical results with the experimental pressure variations (Bowman, 1987) in the porous pipe

the pressure distributions for the low mass flow rates. The pressures in the blowing section decrease due to friction and the acceleration of the flow caused by mass injection, but the pressures in the suction section increase owing to the 
deceleration of the flow by the extraction of mass However, the preswares st the end of the suction section are less than those ot the beginning of the blowing section because of the loss due to friction In these three cases, the pressure distributions at the steady state correspond well to those for low temperature heat pipes and are in agreement with the experimental data

The fourth data profile (case B.5) shows the pressure variatson in the axial direction for the high mass flow rate Unlike the previous three cases, the pressure drop in the blowing section is very large. The pressure ratio at the exit of the blowing section is about 0.4 and this ratio corresponds to a Mach number of $M=1$. After the pressure decreases in the blowing section, the pressure keeps decreasing in the entrance region of the suction section due to the expansion of air even though mass removal occurs Then, the pressure suddenly increases and then continues to increave as the flow slows down. This implies that a shock wave occurs at the place where the pressure changes abruptly. When a shock wave does not exast in the suction section, the pressure is supposed to decrease along the suction section The one-dimensional model predicts the supersonc low and shock wave in the suction section and the comparison of the numencal results and expenmental data shows a good agreement except for the region Immediately after the shock wave

The variations of the pressure, temperature, velocity and deasity at the steady state corresponding to cases $B$ and B 5 are shown in Figs 4 and 5, respectively For the

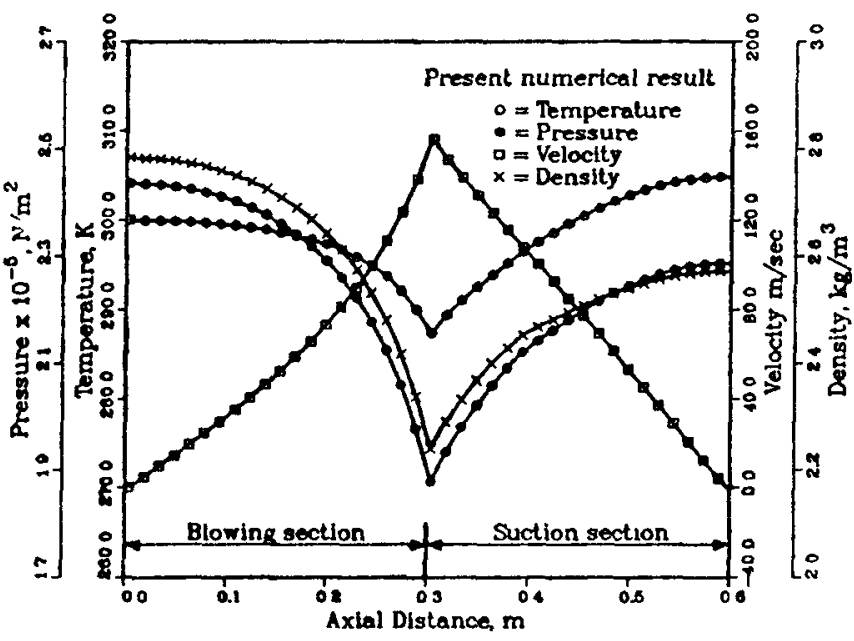

Fig 4 Axial variations of temperature, pressure, velocity and density for case B 4

low mass flow rate, the temperature and density in the blowing section decrease corresponding to the decrease in pressure and the velocity increases due to the mass injection as shown in Fig 4 The Mach number, however, is less than $M=1$ at the exit of the blowing section, so the velocity in the suction section decreases because of the extraction of mass Also, the temperature and density increase in the suction section Figure 5 shows the axal variations of the temperature, pressure, velocity and density for the high mass now rate After the sonic velocity is reached at the exit of the blowing section, the velocity keeps increasing in the suction section until a shock wave occurs Then, the velocity decreases to $U=0$ at the end of the pipe As shown by the density profile, the ait expands near the entrance region of the suction section and then the density suddenly increases after the shock wave

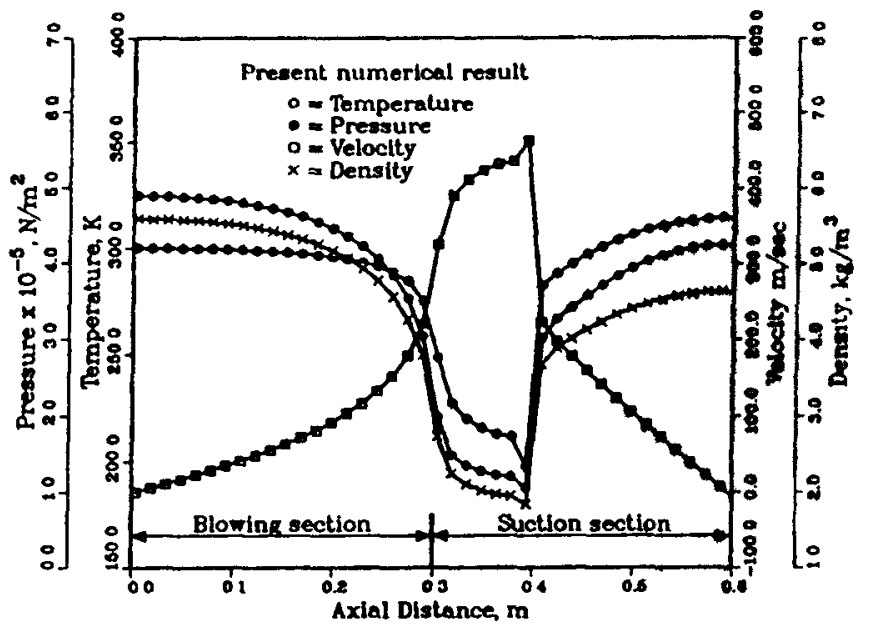

Fig. 5 Axal variations of temperature, pressure, velocity and density for case B.5.

The most interesting aspect in Figs 4 and 5 is the variation of temperature The temperature at the end of the suction section is greater than that at the beginning of the blowing section In the present model viscous discipation is included The Mach number at the entrance of suction section is about $M=05$ for case B.4. Since the present model is one-dimensional, the derivative of the axial velocity with respect to the radius is zero, but the friction effect at the interface between the wall and the vapor is included by using equations $(14-16)$ for the friction factor This effect corresponds to viscous dissipation due to the axial velocity derivative with respect to the radus The increase in temperature is due to viscous dissipation

\section{2) Comparison with Actual Vapor Flow in Cylindrical \\ Heat Pipes}

The model was tested for the actual vapor flow in a sodrum heat pipe corresponding to the expenment given by Ivanovskil et al. (1982) as shown in Fig. 6. The lengths of

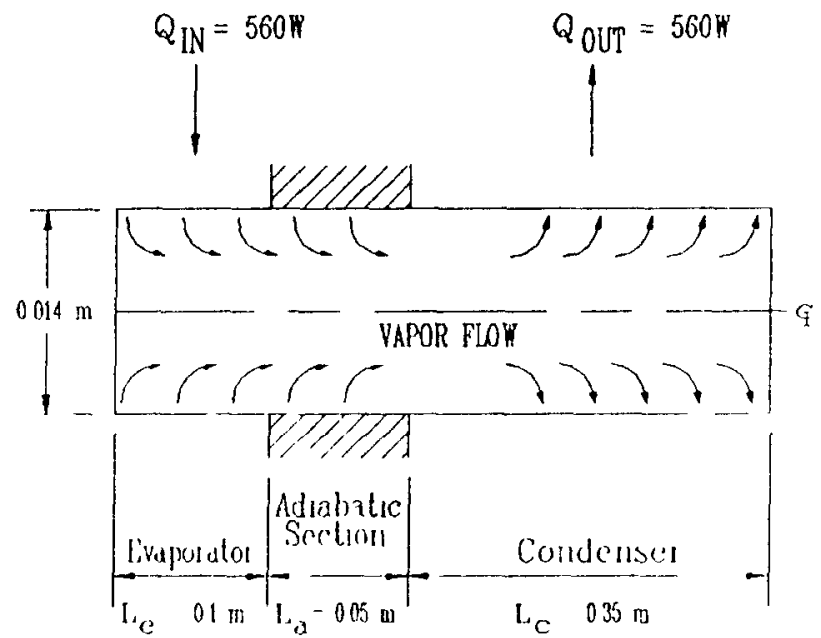

Fig 6 Schematic diagram of model for the sodium vapor flow in the heat pipe 
the evaporator, adiabatic, and condenser sections are 0.1 , 0.05 , and $0.35 \mathrm{~m}$, respectively. The diameter of the vapor space is $0.014 \mathrm{~m}$. The experimental data (Ivanovskii et al., 1982) represents only the saturation temperature and heat transfer rate $(Q=560 \mathrm{~W})$ at the steady state. The initial conditions and actual boundary conditions applied on the surface of the evaporator and condenser are unknown. The present numerical model is transient, however, 80 the initial conditions and history of heat input and output in the evaporator and condenser sections are needed.

For the numerical calculations, the uniform initial temperature of $810 \mathrm{~K}$ is used and the vapor is assumed to be caturated at the initial temperature. Initially, the velocity of the vapor is zero. The same amount of heat $(Q=560 \mathrm{~W})$ is uniformly applied on the surface of the evaporator and the convective boundary condition is used on the surface of the condenser. The reference temperature of $300 \mathrm{~K}$ for the convective boundary condition is employed and the heat transfer coefficient is determined by iteration. At first, an arbitrary initial heat transfer coefficient is guessed. When the numerical results reach the steady state, the saturation temperature at the end cap of the evaporator is compared with the experimental data at the same location. This procedure is repeated until the same temperature is obtained at the steady state. For this test, the heat transfer coefficient of $69.1 \mathrm{~W} / \mathrm{m}^{2}-\mathrm{K}$ is used.

Figure 7 shows the axial variation of the saturation and vajor temperatures, pressure, velocity and density obtained from the present numerical model and the experimentally measured saturation temperature distribution (Ivanovskii et al., 1982). The pressure,

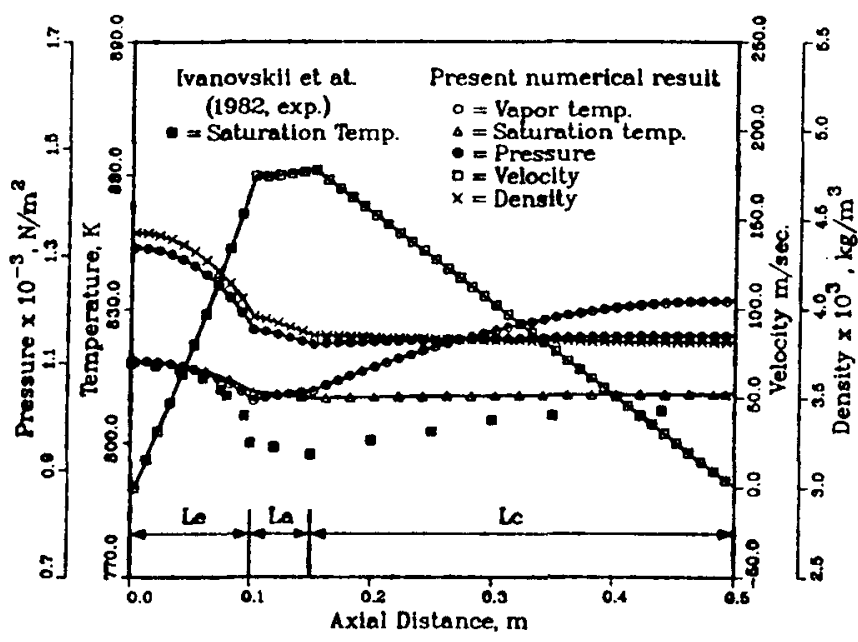

Fig. 7 Axial variations of temperature, pressure, velocity and density of the sodium heat pipe at steady state.

temperature and density in the evaporator decrease and the velocity increases due to the injection of mass and the effect of friction. In the adiabatic section, the vapor temperature increases because of viscous dissipation and the pressure decreases owing to friction at the interface. The density also decreases while the velocity contintes to increase. The vapor temperature in the condenser continues to increase due to viscous dissipation so that the vapor temperature at the end cap of the evaporator is less than that at the end cap of the condenser. The pressure recovery in the condenser is almost negligible. This may result from dominant friction effect at the interface of the condenser compared to the effect of mass extraction in this long condenser. In the adiabatic section a difference between the calculated and measured saturation temperatures is observed, but the trend of the saturation temperature variation is the same. The trend of the vapor temperature in the condenser is quite different from that of the saturation temperature in the same region, so the saturation temperature may not be assumed to be the vapor temperature in the condenser for the one-dimensional model.

The effect of viscous dissipation in the vapor flow for the high temperature heat pipe is investigated as shown in Fig. 8. The vapor temperature at the end cap of the evaporator with viscous dissipation is less than that at the end cap of the condenser. However, the vapor temperature at the end cap of the evaporator without viscous dissipation is almost the same as that at the end cap of the condenser. In the adiabatic section, the vapor temperature with viscous dissipation increases while that without viscous dissipation does not change. Therefore, the viscous dissipation should be taken into account in the energy equation for the high temperature heat pipe.

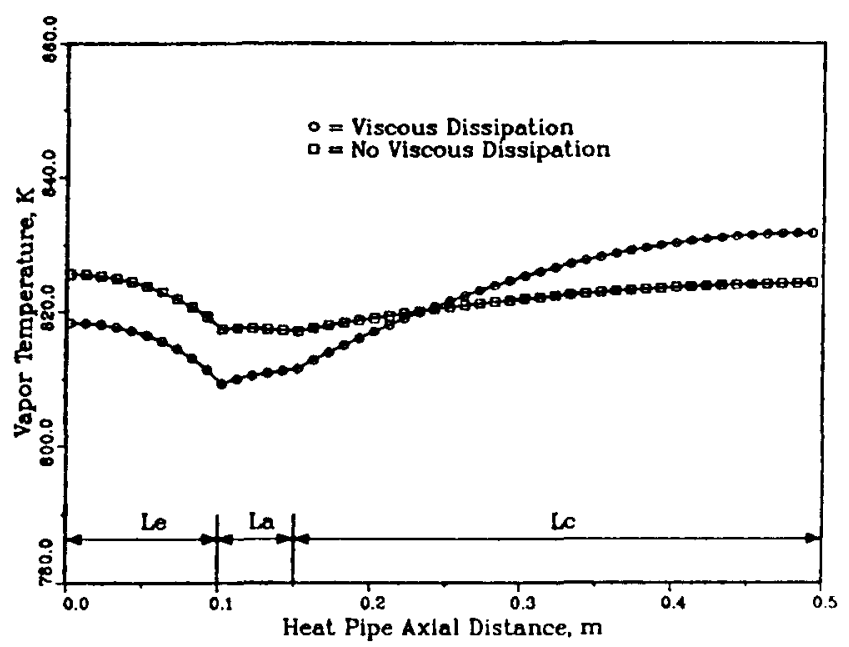

Fig. 8 Comparison of the temperature variations with and without viscous dissipation for actual vapor flow.

\section{CONCLUSIONS}

A model for the transient one-dimensional compressible vapor flow in the cylindrical heat pipe is developed. This model predicts the vapor flow in cylindrical heat pipes as well as simulated heat pipes for the subsonic, sonic, and supersonic tows under transient and steady state conditions. The vapor flow quickly reaches the steady state condition. The distributions of the temperature and pressure during the transient state are quite different from those for the steady state. The viscous dissipation terms play an important role in the energy equation and have to be taken into account. The one-dimensional compressible model predicts the expetimental data well for the cylindrical heat pipe and the simulated heat pipe at the steady state. The experimental data for the transient state are needed to understand clearly the transient bchavior of the vapor flow in the heat pipe both at low and high temperatures. The one-dimensional model can reduce the computational effort needed to solve the vapor low problem. 


\section{ACKNOWLEDGEMENT}

Funding for this work was provided by a joint effort of the NASA Lewis Research Center and the Thermal Energy Group of the Aero Propulaion and Power Laboratory of the U.S. Air Force under contract F33615-88-C-2820.

\section{RRPERENCES}

Anderson, D.A., Tennehill, J.C., and Pletcher, R.H., 1984, Computational Fluid Mechanics and Heat Transfer, Hemisphere Pub. Co., New York.

Bankston, C.A., and Smith, H.J., 1072, "Incompressible Laminar Vapor Flow in Cylindrical Heat Pipes," ASME Paper No. 71-WA/ET-15.

Bowman, W.J., 1987, "Simulated Heat Pipe Vapor Dynamics," Ph.D. Dissertation, Air Force Institute of Technology.

Bowman, W.J., and Hitchcock, J., 1988, "Transient, Compressible Heat-Pipe Vapor Dynamics," Proc. 25th ASME National Heat Transfer Conf, Houston, Texas, pp. $329-337$.

Brovalsky, Y.M., Bystrov, P.I., and Melkinov, M.V., 1976, "The Method of Calculation and Investigation of High-Temperature Heat Pipe Characteristics Taking into Account the Vapor Flow Compressibility, Friction, and Velocity Profile," Proc. 2nd Int. Heat Pipe Conf., pp. $113-$ 122.

Faghri, A., 1986, "Vapor Flow Analysis in a Double-Walled Concentric Heat Pipe," Numerical Heat Transfer, Vol. 10, No. 6, pp. $583-595$.

Faghri, A., 1988, "Performance Characteristics of a Concentric Annular Heat Pjpe - Part II. Vapor Flow Analysis," Proc. of the 1988 National Heat Transfer Conf., Vol. 1, pp. 389-396.

Faghri, A., and Parvani, S., 1988, "Numerical Analysis of Laminar Flow in a Double-Walled Annular Heat Pipe," $\mathbf{J}$. Thermophysics and Heat Transfer, Vol. 2 , No. 3, pp. $165-$ 171.

Issacci, F., Catton, I., Heiss, A., and Ghoniem, N.M, 1988, "Analysis of Heat Pipe Vapor Dynamics," Proc. 25th ASME National Heat Transfer Conf, Houston, Texas, pp. $361-365$.

Ivanovskii, M.N, Sorokin, V.P., and Yagodkin, I.V., 1982, The Physical Principles of Heat Pipes, Clarendon Press, Oxford.

Jang, J.H., 1988, "An Analysis of Startup from the Frozen State and Transient Performance of Heat Pipes," Ph.D. Dissertation, Georgia Institute of Technology.

Levy, E.K., 1968, "Theoretical Investigation of Heat Pipes Operating at Low Vapor Pressures," J. Eng. for Industry, Vol. $90, \mathrm{pp} .547-552$.

Ooijen, H.V., and Hoogendoorn, C.J., 1979, "Vapor Flow Calculations in Flat-Plate Heat Pipe," AIAA J., Vol. 17, No. 11 , pp. $1251-1259$.

Tien, C.L., and Rohani, A.R., 1974, "Analysis of the Effects of Vapor Pressure Drop on Heat Pipe Performance," Int. J. Heat Mass Trans., Vol. 17, No. 1, pp. $61-67$. 


\begin{tabular}{|c|c|c|c|c|c|}
\hline & \multicolumn{5}{|c|}{ Report Documentation Page } \\
\hline 1 & $\begin{array}{l}\text { Report No } \\
\text { NASA CR-185119 }\end{array}$ & \multicolumn{2}{|c|}{ 2. Government Accession No. } & \multicolumn{2}{|c|}{ 3. Recipient's Catalog No. } \\
\hline \multirow[t]{2}{*}{4} & & \multicolumn{2}{|l|}{$\begin{array}{l}5 \text { Report Date } \\
\text { July } 1989\end{array}$} \\
\hline & \multicolumn{3}{|c|}{ Analysis of the Transient Compressible Vapor Flow in Heat Pipe } & \multicolumn{2}{|c|}{ 6. Performıng Organızation Code } \\
\hline \multirow[t]{3}{*}{7} & \multicolumn{3}{|l|}{ Author(s) } & \multicolumn{2}{|c|}{8 Performing Organization Report No } \\
\hline & \multirow{2}{*}{\multicolumn{3}{|c|}{ Jong Hoon Jang, Amir Faghri, and Won Soon Chang }} & None & $(E-4945)$ \\
\hline & & & & \multicolumn{2}{|c|}{$\begin{array}{l}10 \text { Work Unit No } \\
586-01-21\end{array}$} \\
\hline \multirow[t]{2}{*}{9} & \multirow{2}{*}{\multicolumn{3}{|c|}{$\begin{array}{l}\text { Performing Organization Name and Address } \\
\text { Wright State University } \\
\text { Department of Mechanical Systems Engineering } \\
\text { Dayton, Ohio } 45435\end{array}$}} & \multicolumn{2}{|c|}{11 Contract or Grant No. } \\
\hline & & & & \multicolumn{2}{|c|}{$\begin{array}{l}\text { 13. Type of Report and Period Covered } \\
\text { Contractor Report } \\
\text { Final }\end{array}$} \\
\hline 12 & \multicolumn{3}{|c|}{$\begin{array}{l}\text { Sponsorng Agency Name and Address } \\
\text { National Aeronautics and Space Administration } \\
\text { Lewis Research Center } \\
\text { Cleveland, Ohio 44135-3191 }\end{array}$} & \multicolumn{2}{|c|}{ 14. Sponsoring Agency Code } \\
\hline 15 & \multicolumn{5}{|c|}{$\begin{array}{l}\text { Project Manager, Albert J. Juhasz, Power Technology Division, NASA Lewis Research Center; Jong Hoon Jang } \\
\text { and Amir Faghri, Dept. of Mechanical Systems Engineering, Dayton, Ohio } 45435 \text {; Won Soon Chang, Wright } \\
\text { Research and Development Center, Wright-Patterson AFB, Ohio } 45433 \text { (work funded by Air Force Contract } \\
\text { F336 15-88-C-2820). Jong Hoon Jang, presently with Sverdrup Technology, Inc., NASA Lewis Research Center } \\
\text { Group, Cleveland, Ohio } 44135 \text {. Prepared for the 26th National Heat Transfer Conference sponsored by the } \\
\text { American Society of Mechanical Engineers, Philadelphia, Pennsylvania, August 6-9, } 1989 \text {. }\end{array}$} \\
\hline 16. & \multicolumn{5}{|c|}{$\begin{array}{l}\text { The transient compressible one-dimensional vapor flow dynamics in a heat pipe is modeled. The numerical results } \\
\text { are obtained by using the implicit non-iterative Beam-Warming finite difference method. The model is tested for } \\
\text { simulated heat pipe vapor flow and actual vapor flow in cylindrical heat pipes. A good comparison of the present } \\
\text { transient results for the simulated heat pipe vapor flow with the previous results of a two-dimensional numerical } \\
\text { model is achieved and the steady state results are in agreement with the existing experimental data. The transient } \\
\text { behavior of the vapor flow under subsonic, sonic, and supersonic speeds and high mass flow rates are } \\
\text { successfully predicted. The one-dimensional model also describes the vapor flow dynamics in cylindrical heat } \\
\text { pipes at high temperatures. }\end{array}$} \\
\hline 17 & \multicolumn{2}{|c|}{$\begin{array}{l}\text { Heat pipe; Vapor flow; Transient; Compressible; } \\
\text { Sonic and supersonic velocities }\end{array}$} & \multicolumn{3}{|c|}{\begin{tabular}{|c|}
18 Distribution Statement \\
Unclassified - Unlimited \\
Subject Category 34
\end{tabular}} \\
\hline & $\begin{array}{c}\text { Security Classif. (of this report) } \\
\text { Unclassified }\end{array}$ & 20 Security & $\begin{array}{l}\text { of this page) } \\
\text { lassified }\end{array}$ & $\begin{array}{c}\text { 21. No of pages } \\
10\end{array}$ & $\begin{array}{r}\text { 22. Price* } \\
\mathrm{A} 02\end{array}$ \\
\hline
\end{tabular}

NASA FORM 1626 OCT $86 \quad$ *For sale by the Natıonal Technical Information Service, Springfield, Virginia 22161 